\title{
When Will Coronavirus Disease-19 Patients be allowed to Work at the Office Again?: A Literature Study
}

\author{
Cokorda Agung Wahyu Purnamasidhi ${ }^{1 *}$, Ni Made Dewi Dian Sukmawati ${ }^{2}$, Anak Agung Ayu Yuli Gayatri ${ }^{2}$, \\ I Made Susila Utama ${ }^{2}$, I Ketut Agus Somia ${ }^{2}$, Ketut Tuti Parwati Merati ${ }^{2}$ \\ ${ }^{1}$ Department of Internal Medicine, Udayana University, Udayana University Hospital, Denpasar, Indonesia; ${ }^{2}$ Department \\ of Tropical and Infectious Diseases, Division Internal Medicine, Udayana University, Sanglah General Hospital, Denpasar, \\ Indonesia
}

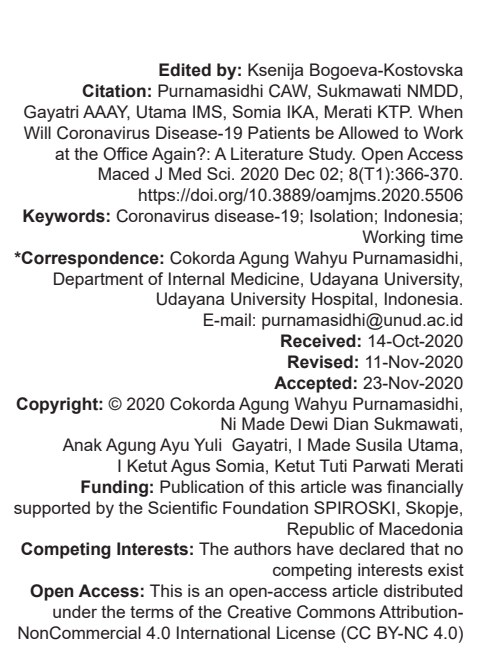

\section{Abstract}

As numbers of coronavirus disease (COVID)-19 cases in the world rises gradually, both from unending first waves and resurging waves following successful reduction of cases on first waves, both the world and healthcare workers face an impending situation in the near future. For the world, the question may be, "When will we be allowed to work at our office again?" For caregivers, the question will be, "What may happen if over capacitance of healthcare facilities resumes until indeterminate time?" New published guidelines by WHO on clinical management of COVID19 provided most recent recommendations on criteria for stopping isolation of COVID-19 patients based on new findings that patients positive of severe acute respiratory syndrome coronavirus 2 is not always transmitting virus to surroundings. Furthermore, criteria for terminating isolation are suitable for all COVID-19 cases regardless of the location of isolation or the severity of the disease without the requirement of repeated swab examinations. This further gives an advantage by lowering healthcare costs and effective allocation of health resources. Even if a negative swab result is still a condition to be deemed not to be able to transmit the virus, this should not be a barrier for someone to return to their normal activity and lifestyle while waiting for the test swab results. In the end, the choice whether to pursue a result that has no clear benefits by allocating funds for repeated swab tests at expensive costs and ignoring the productivity of professionals by carrying out prolonged isolation or to optimize the resources at our disposal.

\section{Introduction}

An important question often asked by a confirmed coronavirus disease (COVID)-19 patient is: "Doc, when will I be allowed to work at my office again?" followed by "Can I still transmit this virus to other people or my family?"

During these times - at least until this paper is written - patients recovered from COVID-19 may not simply be happy after getting past the acute phase of the disease. This is because at the next phase they will still need to wait for the next re-swab schedule, with the goal to find whether the person is still positive or is already negative of COVID-19, in other words, is the person still able to transmit the virus or not. During these waiting moments, they need to be isolated, unable to go to the office because of the stigma that the patient may still transmit the virus to other people, both at home and at the working environment, therefore, unable to contact closely and need to be physically distanced/stayed away from. Therefore, these long and rigorous processes may inflict a heavy psychological burden for a person recovered from COVID-19; and for patients without any symptoms, it may be something heavier than the disease itself. On the other side, there is no certainty in the matter of time that the following swab test will be negative. No matter how many times the test is conducted, there is no guarantee that the next one will be negative. WHO stated that the test may result in reactivity even though it was conducted weeks after the first infection, while CDC in August 2020 showed that a patient recovered from COVID-19 tested 3 months after first infection may still be reactive to COVID-19 swab test [1].

The question is: If that is the reality and that a reactive swab test is identical to virus transmission, is a negative swab test result an absolute term for someone to live and move normally? Is there prove that someone with a reactive swab test result is still able to transmit severe acute respiratory syndrome coronavirus (SARSCoV)-2? [2]. 


\section{What is the Risk of Transmitting SARS-CoV-2?}

COVID-19 is caused by an easily transmitted virus called SARS-CoV-2. After someone was exposed to this virus, the RNA virus will be able to be detected at the patient 1-3 days before the occurrence of any symptom. On the upper respiratory tract, viral load will reach its peak in the $1^{\text {st }}$ week following exposure (highest on the $4^{\text {th }}$ day after the symptoms occurred), followed by a progressive decrease over time. On feces and lower respiratory tract, viral load will reach its peak 2 weeks after first exposure. There is a tendency that the RNA virus will be detected longer on people with severe symptoms and immunodeficiency and that there is a connection between transmissibility and onset of symptoms. The highest risk for transmission occurs during symptoms onset and 5 days following the first infection. Usually, 5-10 days after SARS-CoV-2 infection, patients infected will be producing neutralizing antibody progressively. The production of this antibody will lower the risk of infection. Based on these data, 10 days following infection, the risk of patient transmitting COVID-19 is relatively low [3], [4].

\section{Is SARS-CoV-2 Transmissible in a Reverse Transcriptase-polymerase Chain Reaction (RT-PCR) Positive Patients?}

COVID-19 (SARS-CoV-2) is confirmed by the presence of the RNA virus detected through molecular tests, usually RT-PCR. The presence of RNA viruses in a person does not always mean that the person is infectious and can transmit the virus to other people [5], [6]. There are factors that determine the risk of transmission, namely the ability of the virus to replicate, symptoms such as coughing, infectious droplets, and environmental conditions and factors associated with the infected individual [4], [5].

In many viral diseases (e.g., SARS-CoV, MERS, influenza virus, Ebola virus, and Zika virus), it is well known that viral RNA can be detected for a long time after the infectious virus has ceased to exist. For example, measles virus, its viral RNA can still be detected 6-8 weeks after the infectious virus itself has disappeared. The immune system can neutralize the virus that prevents subsequent infections but does not eliminate nucleic acids, which remain detectable by RT-PCR, which will gradually decrease over time [5], [7], [8].

In COVID-19, the duration of infectious viral transmission period varies widely and may depend on the severity of the disease and the patient's immune condition. A study obtained repeated viral RNA tests with negative results in $90 \%$ of cases with mild disease, while severe disease had positive results with a longer period of time [6], [9]. Zhou et al. reported that the median duration of the viral transmission period in COVID-19 patients who were in severe or critical condition was 31 days (range of 18-48 days) [7], [9], [10]. Wolfel et al. reported that COVID-19 patients with mild to moderate symptoms did not find the SARS-CoV-2 virus cultured from airway samples 8 days after of onset of symptoms. Other studies with varying degrees of disease have shown an inability to multiply the virus after days 7-9 of symptom onset [4], [8], [11]. In a study of 129 critically ill COVID-19 patients, of whom 30 were immunocompromised, the mean duration of viral transmission as measured by culture was 8 days after onset, with the interquartile range of 5-11 days [9], [12], [13]. The likelihood of detection of the virus on culture is $<5 \%$ after 15.2 days of symptoms. This study as well as several other studies have reported a correlation between decreased infectivity with decreased viral load and increased neutralizing antibodies. Although viral RNA can be detected by RT-PCR even after symptoms have disappeared, the amount of viral RNA detected is substantially reduced over time and is generally below the threshold for the virus' ability to replicate. Therefore, it is a safe approach to combine the time between the onset of symptoms and the disappearance of symptoms based on current data [4], [14].

\section{When Can Patients Return to Work After Confirmed of COVID-19?}

On 27 May 2020, WHO published guidelines on clinical management of COVID-19 and provided most recent recommendations on the criteria for stopping isolation of COVID-19 patients. The updates are based on new findings that asymptomatic patients still tested positive for the COVID-19 virus (SARS-CoV-2) with RT-PCR even for the following weeks. Even though the test result is still positive, it turns out that it cannot infect other people. The criteria for terminating isolation are suitable for all COVID-19 cases, regardless of the location of isolation or the severity of the disease and without requiring a repeat swab examination, namely: [4], [15], [16], [17]

1. For symptomatic patients: 10 days after symptom onset, plus at least 3 additional days without symptoms (including no fever and no respiratory symptoms)

2. For asymptomatic cases: 10 days after testing positive for SARS-CoV-2.

This latest $\mathrm{WHO}$ recommendation (27 May) differs from and also revises the previous 
recommendation (12 January) that patient isolation is terminated upon clinical recovery and two negative RT-PCR results are obtained in sequential samples taken at least $24 \mathrm{~h}$ apart [10].

Based on the CDC, there are three principles to stop isolation of COVID-19 patients, namely "symptombased strategies," "time-based strategies," and "testbased strategies." The "symptom-based strategy" is the CDC's latest revised release for isolation for symptomatic COVID-19 patients. Patients may move out from isolation and return to work if the following three conditions are met [10], [17], [18]:

1. At least 10 days from when symptoms first appeared; and

2. At least $24 \mathrm{~h}$ since the last fever without using fever-reducing drugs; and

3. All COVID-related symptoms (e.g., cough and shortness of breath) have improved.

The "time-based strategy" remains valid for patients with a positive but asymptomatic swab test (i.e., 10 days of isolation from the date of positive test), as well as for patients (including healthcare professionals) with severe to critical illness or who are severely immunocompromised. Adults, the duration is at least 10 days-20 days after symptom onset, while the "test-based strategy" is no longer resisted by the CDC (except in severely immunocompromised patients). The reason it is no longer considering a test-based strategy is that it will result in prolonged isolation because the SARS-CoV-2 RNA virus is still detected, but the patient is not able to transmit the virus anymore (CDC, update August 10) [11], [19].

In our hospital (a University Hospital in Bali, Indonesia), when our government adopts the old criteria from $\mathrm{WHO}$, we used 2 times negative results of PCR for stopping isolation, many problems happen. In many cases, sometimes patients already did not have any symptoms again, but the PCR result is still positive. In our hospital from April until June 2020, 42 $(16.5 \%)$ patients have hospitalized for more than 14 days, even though they do not have any symptom, but the PCR results were positive. One of the patient, already hospitalized 58 days, but she did not have any symptom since day 6 after admission. Since July 2020, our government adopts the newest WHO guidelines. From that time, the length of patient care can be shorter. The average patient was treated for 13-14 days.

\section{Public Health Impact}

This study focuses on the exploration of COVID-19 patients isolation time and factors in relation to isolation time. We also did a literature-based critical analysis on the exact necessity of prolonged isolation time as well as repeated swab test in deciding whether a COVID-19 patient is to be released from hospitalization or not. Based on the finding of this study, we could conclude that approximately 2-weeks isolation time starting from symptoms onset is safe and reliable enough as a standard for COVID-19 patient release, especially those with mild symptoms. Thus, the result of this study poses as scientific-based supporting data to aid effective decision making for stakeholders in the management of health resources regarding COVID-19 inpatients and hospitalization, namely, a faster release of COVID-19 patients after 14 days of hospitalization means there will be more space of new patients, specifically those critically ill and in need of active supervision. Other than hospital bed and facilities, fewer patients to tend also means healthcare team could also put more focus on urgent and severe patients, increasing productivity and lessening burden, which might lead to medical errors. The results from this study could also be considered by the government and local ministry of health to reconsider and perhaps change their old way of managing COVID-19 funds. The previous statement refers to the fact that "unnecessary" fund spent on hospital fee for mild or recovered patients with no symptoms who are fully capable of home-care and self-quarantine is a waste of resources, which could be allocated more effectively for other aspects of COVID-19 management [19], [20].

\section{Perspective}

Based on research evidence and recommendations from $\mathrm{WHO}$ and $\mathrm{CDC}$ above, of course, it will raise a belief that the negative swab criteria as a reference for someone to be able to stop their isolation and be allowed to return to work are no longer relevant to be applied because there is no rational basis for using the negative swab reference to be considered cured of COVID-19.

Sometimes professionals who are accustomed to critical thinking who always put forward evidence (evidenced based) forget about this. It may be that this is based on excessive worry and fear of contracting so that in the end, they put forward baseless opinions and no longer consider the aftereffects as a result of improper application of guidelines.

In this world, no one is the same, everyone has their own uniqueness. Likewise, there is no diagnosis of the same disease, which will give the same outcome. It is commonly known in medical circles that the management of disease must apply the principles of personalized medicine and an individualized treatment approach. Implementing an action must be personal or individual and in accordance with the conditions at that time. This also applies for patients with confirmed 
COVID-19. Before deciding on the next step (e.g., the length of time for isolation and the need for a re-swab for evaluation), an evaluation of each condition must be carried out individually, especially the presence or absence of symptoms (mild, moderate, severe, or critical), the presence or absence of sequelae that may describe the severity of the complications that occur, the presence or absence of comorbid conditions, and so on. This is so that the available resources, which are generally limited, will actually be used effectively and efficiently and can be allocated to other needs that are more appropriate. From patient's perspective, there is a sense of satisfaction after having received proper care, which has been adjusted to their personal conditions.

Even if a negative swab is still a condition need to be met to be deemed not to transmit the virus, then this should not be a barrier for someone to be able to return to their normal activity and lifestyle while waiting for the test swab results. The person (the "patient") is clear, has been confirmed with COVID-19, so with this clear status, it is easier to be able to implement stricter transmission prevention patterns, for example, using N95 masks or the equivalent, especially when treating patients for health workers. The application of a more stringent pattern of prevention of transmission over a certain period of time in patients with confirmed COVID-19 feels more human while waiting for a laboratory examination schedule (if necessary) rather than isolation.

Another thing that needs to be paid attention to regarding the mere provision of the negative swab is the risk of a shortage of staff/professionals to care for patients, especially if there is a significant spike in confirmed positive COVID-19 cases affecting medical professionals. At the same time, to anticipate this, health facilities must be prepared to face potential staff shortages and have a plan and process to address them, including by implementing the latest $\mathrm{WHO}$ and CDC recommendations.

WHO does not prohibit a country from continuing to use the recommendation issued at the beginning of the pandemic, namely 2 negative swabs with a distance of at least $24 \mathrm{~h}$ as a criterion for stopping isolation. On the other hand, we all certainly agree that the facilities and infrastructure that we have related to COVID-19 are still very limited, still far from the minimum required. Therefore, the use of sophisticated and expensive laboratories such as the RT-PCR examination for SAR-CoV-2 virus must be right on target, allocated appropriately, so that it can reach more target patients. How much money can be saved if the RT-PCR examination is only done once for each patient for diagnostic purposes only, without re-examinations that may need to be repeated many times with a target of only negative swab results? A laboratory-based approach may still have a place for COVID-19 patients, but of course, it is selective, only in patients with certain conditions based on the evaluation of a competent doctor.
In the end, the choice is ours, whether to pursue something that has no clear benefits (keep allocating funds for swab tests at this inexpensive cost and ignore the productivity of professionals by carrying out prolonged isolation), or whether we will optimize the resources we have at our disposal. Our country, Indonesia, is a country that belongs to the developing country category with limited resources, so if there is a good choice and at a much cheaper cost, of course, we will choose it.

\section{Conclusion}

Based on the evidence that shows that the virus can no longer be cultured (no ability to replicate) after 9 days from the onset of symptoms (especially in patients with mild disease), it is safe to stop isolating COVID-19 patients based on clinical criteria with a minimum isolation time of 13 days since symptom onset, and not strictly based on repeated PCR results. Whereas in patients with severe or critical symptoms, as well as those with severe immune disorders, a laboratory-based approach (measurement of viral load and neutralizing antibodies) may be helpful in making decisions about whether or not a person should undergo prolonged isolation [12].

\section{References}

1. Duration of Isolation and Precautions for Adults with COVID19. 2020. Centre for Disease Control and Prevention. Available from: https://www.cdc.gov/coronavirus/2019-ncov/hcp/durationisolation.html. [Last accessed on 2020 Sep 10].

2. Loeb M, Alhazzani W, Mertz D, Singhal N, Chagla Z, Jaeschke R, et al. Coronavirus Disease 2019 (COVID-19). McMaster Textbook of Internal Medicine; 2020. Available from: https:// www.empendium.com/mcmtextbook/chapter/B31.II.18.1.12. [Last accessed on 2020 Sep 18].

3. Guidance on Coronavirus Disease 2019 (COVID-19) for Transplant Clinician, The Transplantation Society; 2020. Available from: https://www.tts.org/23-tid/tid-news/657-tidupdate-and-guidance-on-2019-novel-coronavirus-2019-ncovfor-transplant-id. [Last accessed on 2020 Sep 08].

4. Criteria for Releasing COVID-19 Patients from Isolation. Ghanaian German Economic Association; 2020. Available from: http://www.ggea.net/news/criteria-for-releasing-covid-19patients-from-isolation. [Last accessed on 2020 Oct 03]. https:// doi.org/10.1016/j.phrs.2020.105063

5. Atkinson B, Petersen E. SARS-CoV-2 shedding and infectivity. Lancet J 2020;395:1339-40. https://doi.org/10.1016/ s0140-6736(20)30868-0

PMid:32304647

6. Cennimo D, Bergman SJ. Coronavirus Disease 2019 (COVID19). Medscape; 2019. Available from: https://www.emedicine. medscape.com/article/2500114-overview. [Last accessed on 
2020 Oct 03].

7. Zhou F, YuT, Du R, Fan G, Liu Y, Liu Z, et al. Clinical course and risk factors for mortality of adult inpatients with COVID-19 in Wuhan, China: A retrospective cohort study. Lancet 2020;395:1054-62. https://doi.org/10.1016/s0140-6736(20)30566-3

PMid:32171076

8. Wolfel R, Corman VM, Guggemos W, Seilmaier M, Zange S, Müller MA, et al. Virological assessment of hospitalized patients with COVID-19. Nature 2020;581:465-9. https://doi.org/10.1038/ s41586-020-2196-x PMid:32235945

9. Rees E, Nightingale ES, Jafari $Y$, Waterlow N, Clifford S, Pearson CA, et al. COVID-19 length of hospital stay: A systematic review and data synthesis. BMS Med 2020;2020:4780. https:// doi.org/10.1186/s12916-020-01726-3

10. Sisay $O$, Abdullah $M$, Smith E. Planning for the Worst and Hoping for the Best: Forecasting Covid-19 for Sub-Saharan Africa. Tony Blair Institute for Global Change; 2020. Available from: https:// www.institute.global/advisory/planning-worst-and-hoping-bestforecasting-covid-19-sub-saharan-africa. [Last accessed on 2020 Sep 05]. https://doi.org/10.1016/j.parkreldis.2020.09.042

11. Rhee C, Kanjilal S, Baker M, Klompas M. Duration of severe acute respiratory syndrome coronavirus 2 (SARS-CoV-2) infectivity: When is it safe to discontinue isolation? Clin Infect Dis 2020;1:ciaa1249. https://doi.org/10.1093/cid/ciaa1249 PMid:33029620

12. Kumar D. C4 article: Implications of COVID-19 in transplantation. Am J Transplant 2020;2020:16346.

13. Trisnawati I, Khair R, Puspitarani D, Fauzi A, Gunadi. Prolonged nucleic acid conversion and false-negative RT-PCR results in patients with COVID-19: A case series. Ann Med Surg
2020;59:224-8. https://doi.org/10.21203/rs.3.rs-39961/v1 PMid:33052256

14. Bahadur G, Acharya S, Muneer A, Huirne J, Lukaszuk M, Doreski $\mathrm{P}$, et al. SARS-CoV-2: Diagnostic and design conundrums in the context of male factor infertility. RBMO J 2020;41:365-9. https://doi.org/10.1016/j.rbmo.2020.05.014 PMid:32565229

15. D'Ardes D, Pontolillo M, Esposito L, Masciarelli M, Boccatonda A Rossi I, et al. 2020. Duration of COVID-19: Data from an Italian cohort and potential role for steroids. Microorganisms 2020;8:1327. https://doi.org/10.3390/microorganisms8091327

16. Sze S, Pan D, Williams C, Barker J, Minhas J, Miller C, et al. The need for improved discharge criteria for hospitalised patients with COVID-19-implications for patients in long-term care facilities. 2020;2020:afaa206. https://doi.org/10.1093/ageing/afaa206

17. Glands $H$, Gredmark-Russ $S$, Olausson M, Falck-Jones S, Varnaite R, Christ W, et al. Shedding of Infectious SARS-CoV-2 from Airways in Hospitalized COVID-19 Patients in Relation to Serum Antibody Responses. medRxiv; 2020. https://doi. org/10.1101/2020.09.11.20191940

18. Curigliano G, Banerjee S, Cervantes A, Garassino MC, Garrido P, Girard N, et al. Managing cancer patients during the COVID-19 pandemic: An ESMO multidisciplinary expert consensus. Ann Oncol 2020;31:1320-35.

19. Folgueira M, Luczkowiak J, Lasala F, Perez-Rivilla A, Delgado R. Persistent SARS-CoV-2 Replication in Severe COVID-19. medRxiv; 2020. https://doi.org/10.1101/2020.06.10.20127837

20. Tomacruz S. How PH Recorded Over 38.000 COVID-19 Recoveries in a Single Day; 2020. Available from: https://www. rappler.com/nation/how-philippines-recorded-over-38000covid-19-recoveries. [Last accessed on 2020 Jul 30]. 